\title{
Conservation of the Nuclear Receptor Response Element in HIV-1 LTRs: A Possible PPAR Response Element?
}

\author{
Tara Hurst \\ School of Science and Technology, Nottingham Trent University, Clifton Lane, Nottingham NG11 8NS, UK \\ Correspondence should be addressed to Tara Hurst; tara.hurst@ntu.ac.uk
}

Received 26 March 2013; Accepted 24 April 2013

Academic Editors: F. Christ, A. Cid-Arregui, A. Doglio, and C. Torti

Copyright (C) 2013 Tara Hurst. This is an open access article distributed under the Creative Commons Attribution License, which permits unrestricted use, distribution, and reproduction in any medium, provided the original work is properly cited.

Infection with HIV-1 continues to be a threat to public health. Successful antiretroviral therapy has reduced the risk of developing AIDS but cannot fully eradicate the virus due to latent proviral sequences remaining in infected cells. The $5^{\prime}$-long terminal repeat (LTR) of HIV-1 is critical for the regulation of transcription of the viral RNA and subsequent production of new viral particles. Indeed, the regulation of transcription relies upon the binding of host cell transcription factors and associated regulatory proteins to the LTR. Recently, it has been found that the treatment of cells with ligands of a number of nuclear receptors (NRs) resulted in inhibition of HIV-1 replication. This inhibition likely occurs via effects on other proteins that bind to the $5^{\prime}$-LTR, notably NF- $\kappa$ B. Here, the possible binding site of one NR, the peroxisome proliferator-activated receptor (PPAR), in the HIV-1 $5^{\prime}$-LTR is analysed within isolates of the virus. Given the high mutation rate of HIV-1, it is striking that this region remains conserved in more recent isolates from geographically distinct regions. This work provides a rationale for further study of the binding site recognised by PPAR in the HIV-1 $5^{\prime}$-LTR.

\section{Introduction}

The human immunodeficiency virus (HIV-1) remains a major threat to human health in many parts of the world although the incidence of AIDS has declined due to the development of antiretroviral therapy [1]. Advances in treatments have emerged from knowledge of how the virus replicates within host cells. Following infection, the RNA genome of HIV-1 is reverse transcribed and integrated into the host chromosomes as a provirus. The genome structure of HIV-1 includes $5^{\prime}$ - and $3^{\prime}$-long terminal repeats (LTRs), as well as coding sequences for viral proteins (Figure 1(a)). The replication of HIV-1 is controlled by cellular proteins that bind to the $5^{\prime}$-LTR of the integrated provirus $[2,3]$, as well as to downstream regulatory elements within the virus protein coding sequence [4]. One important class of proteins that interact with the $5^{\prime}$-LTR is the nuclear receptor (NR) superfamily, members of which bind to a specific response element termed NRRE-1-DE (Figure 1(b)) [5]. In particular, the heterodimer formed of the peroxisome proliferatoractivated receptor (PPAR) and retinoid X receptor (RXR) was able to induce the LTR reporter gene in the presence of the ligands clofibric acid and 9-cis-retinoic acid, respectively [5].

The PPARs are typically ligand-activated NRs which have well-characterised roles in the regulation of cellular metabolism. There are three known isoforms of PPARs, each with distinct functions and tissue-specific expression. PPAR $\alpha$ is typically involved in the regulation of fatty acid oxidation and is highly expressed in tissues with elevated fatty acid catabolism, including the liver, skeletal muscle, and heart [6]. Interestingly, there is evidence of differential expression of PPAR $\alpha$ in males and females, with further indications of a role for sumoylated PPAR $\alpha$ in the protection against oestrogen-induced hepatotoxicity [6]. The PPAR $\gamma$ isoform exists in seven isotypes (PPAR $\gamma 1-7)$, with most of these types being expressed in adipose tissue except PPAR $\gamma 4$ and PPAR $\gamma 5$, which are macrophage-specific [7]. PPAR $\gamma$ in adipose tissue is important in regulating fatty acid uptake, adipocyte differentiation, glucose homeostasis, and insulin sensitivity [7]. In contrast to the other isoforms, $\operatorname{PPAR} \beta / \delta$ is expressed ubiquitously and is thought to have a role in general cellular reactions, as well as a particular role in skin biology 


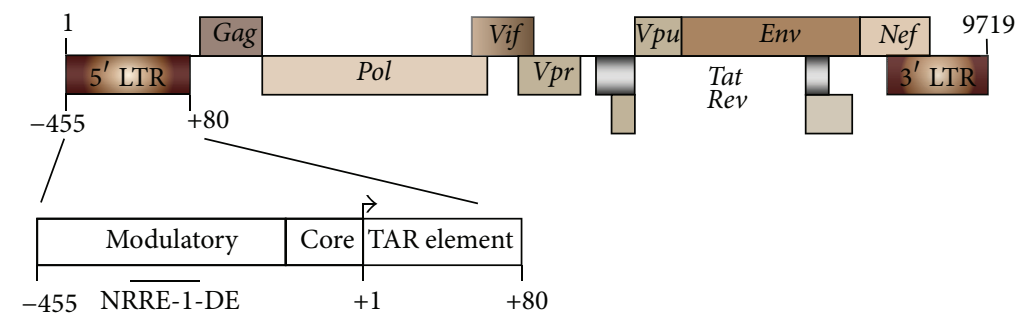

(a)

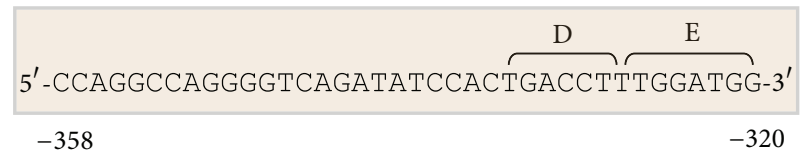

(b)

FIgure 1: The location of the NRRE-1-DE in the HIV-1 $5^{\prime}$-LTR. (a) The HIV-1 genome has a $5^{\prime}$-LTR, protein coding sequences ( $g a g$, pol, vif, $v p r$, tat, rev, vpu, env, vif) and a $3^{\prime}$-LTR (adapted from Figure 1 in [32]). The NRRE-1-DE is located within the modulatory region of the $5^{\prime}$-LTR. The nucleotides are numbered below the diagram according to their location upstream of the TAR element, which is denoted as nucleotide +1 . Numbering beginning from the $5^{\prime}$-end of the LTR is also indicated above the diagram. (b) The sequence of the NRRE-1-DE, with the D and $\mathrm{E}$ heptanucleotide repeats, is indicated above the sequence (adapted from Figures 1(a) and 2(a) in [5]).

and wound healing [6]. Ligands for the PPARs include endogenous fatty acids, as well as the synthetic agonists, the fibrates $(\operatorname{PPAR} \alpha)$, and thiazolidinediones $(\operatorname{PPAR} \gamma)[8]$.

The activation of gene transcription by PPARs is thought to only occur following ligand binding to the receptor [9] and to require the cooperation of the $\operatorname{RXR}[10,11]$. In the absence of ligand, PPAR-RXR heterodimers bind to the PPAR response element (PPRE) within the promoters of target genes [9] and this bound, unliganded PPAR-RXR can repress gene expression $[8,12]$. In addition to control via ligand binding, PPARs are regulated by interaction with corepressor and coactivator complexes. There have been more than 300 cofactors described for the NRs [13], suggesting that diverse complexes of cofactors contribute to NR-mediated transcriptional activation. Corepressors can bind to PPARs in the absence of ligand; the binding of ligands to the receptor results in a conformational change in the PPAR structure which causes the dissociation of the corepressor and the association of coactivator complexes [12, 14]. Additional mechanisms of PPAR action have been described, including trans-repression, constitutive activation, and selective control by cofactors $[8,9,12,14]$. Thus, the general model of ligandactivated, PPAR-mediated gene transcription is likely a simplified view of PPAR function.

The canonical sequence of the PPRE is a DR1 element that consists of two direct repeats of the consensus sequence $5^{\prime}$-AGGTCA-3' separated by a single nucleotide [22]. However, functional PPREs have been identified to vary widely from this sequence (Table 1 ). The first sequence described was $5^{\prime}-$ TGACCTtTGTCCT-3' [16] and this was later refined to $5^{\prime}-T G A C C T t / a T G A C C T-3^{\prime}[15]$, showing variability in the spacer nucleotide. The half-site $5^{\prime}-T G A C C T-3^{\prime}$ is a general response element recognised by NRs; however, a PPRE comprising two direct repeats of this site was found to respond to PPAR $\alpha$ stimulation [11]. Other studies identified functional PPREs with very different sequences (Table 1) in several metabolic genes $[15,19,23,24]$. More recently, the consensus sequence $5^{\prime}$-AGGTCAaAGGTCA-3' was used in an algorithm to detect PPAR-responsive genes within the human genome [25]. This consensus was derived from analysis of 73 reported PPREs, but there is variability in the nucleotide at each position within this consensus; indeed, a novel PPAR-associated sequence was identified and found to be more conserved than this PPRE [25]. Some of this variability could be accounted for by the different species in which the studies have been carried out, since it has been found that the PPRE of a given gene can vary among species $[17,20,21,26]$.

The abovementioned variability in the PPRE sequences suggests that the DNA sequence of the PPRE alone does not determine PPAR binding. The DR1 element is considered to be highly promiscuous, binding to several members of the NR superfamily [27]. Although particular nucleotides within this sequence were identified to indicate the binding preference of the particular NR, the sequence context of the DR1 element contributed to receptor specificity and functionality [27]. Further to this, there are conflicting reports about the role of $5^{\prime}$ flanking nucleotides of the PPRE. Some studies reported that the $5^{\prime}$-proximal sequence was important in PPAR binding [19] and even provided specificity for a given PPAR isoform $[24,28]$. This was refuted by the computational study, which did not find the core or flanking nucleotides contributed to isotype specificity [25]. In addition, the cofactor complexes that modulate PPAR function do so via several mechanisms. Importantly, many of the known cofactors are enzymes that regulate histone acetylation and chromatin remodelling, thereby facilitating or impeding gene transcription [14]. Thus, there is greater complexity in the requirements for PPAR binding to DNA than what is generally acknowledged.

Although PPARs have been shown to bind to the NRRE1-DE $[5,29]$, no further work has been reported in which this interaction is characterised. The NRRE-1-DE lies within 
TABle 1: The functional PPRE sequences from several cellular metabolism genes, showing the variability in the half-sites and spacer nucleotides. The half-site sequences are shown in uppercase letters, while the spacer nucleotide is written in lowercase ones.

\begin{tabular}{|c|c|c|c|}
\hline Gene name & Species & PPRE $\left(5^{\prime}\right.$ to $\left.3^{\prime}\right)$ & Reference \\
\hline HMG-CoAS & Not indicated & AGACCTtTGGCCC & {$[15]$} \\
\hline Lipoprotein lipase & Not indicated & TGCCСТtTCCСCC & [15] \\
\hline Acyl-CoA oxidase & Rat & TGACCTtTGTCCT & [16] \\
\hline Acyl CoA oxidase (active) & Human & AGGTCAcTGGTCA & [17] \\
\hline Acyl CoA oxidase (inactive) & Human & AGGTCAgCTGTCA & [17] \\
\hline Peroxisomal enoyl-CoA hydratase/3-hydroxyacyl-CoA dehydrogenase (HD) & Rat & TGACCTaTGACCT & {$[18]$} \\
\hline Malic enzyme-proximal site & Not indicated & GGGTCAaAGTTGA & [19] \\
\hline Adipose differentiation-related protein & Human & AGGTGAaAGGGCG & {$[20]$} \\
\hline Pancreatic-duodenal-homeobox-(PDX-) 1 & Mouse & GGGTACcTCCAGT & {$[21]$} \\
\hline Pancreatic-duodenal-homeobox-(PDX-) 1 & Human & AAGGACcTCCAGT & {$[21]$} \\
\hline
\end{tabular}

what is considered to be a negative regulatory element (NRE) in the $5^{\prime}$-LTR from nucleotides -340 to -184 [3], and early functional studies showed that this region had a repressive effect on viral transcription owing to the binding of particular cellular transcription factors $[30,31]$. It is feasible then that PPAR binding to this region could directly suppress HIV-1 transcription. Interestingly, the heptanucleotide repeats D and $\mathrm{E}$ in NRRE-1-DE are similar in sequence to the functional PPREs of cellular genes described by Schoonjans and colleagues [15]. The aim of the current work was to examine recent isolates of HIV-1 for the presence and conservation of the NRRE-1-DE, particularly the heptanucleotide repeats $\mathrm{D}$ and $\mathrm{E}$ (NRRE-1-DE) identified by Ladias [5]. Further, the NRRE-1-DE sequence could comprise a PPAR binding site, based on the similarity to the functional PPREs. The potential for the NRRE-1-DE to act as a site for negative modulation by PPARs is evaluated.

\section{Materials and Methods}

The HIV-1 LTR sequences available in GenBank were obtained by searching PubMed Nucleotide using the search terms "HIV-1 LTR" and "HIV LTR." Several groups of isolates were analysed for presence of the consensus sequence TGACCT. Among the HIV-1 isolates reported, large datasets from Brazil [33] and Chile [34] did not contain the sequence and were not analysed further. The HIV-1 LTRs from France [35], USA [36], Tanzania [37], and India [38] were analysed for the presence of the motif. The sequences were aligned using Clustal W Omega and the alignments were coloured using Boxshade 3.21 (EMBnet.org). Further, the nucleotide conservation within the motif was analysed using Weblogo (weblogo.berkeley.edu). For the large number of clinical isolates from India, several clones of each isolate were provided as partial sequences [38]. The sequences of the NRRE-1-DE in the clones from these isolates were aligned and coloured using Boxshade 3.21. The clones were analysed using the Blosum62 distance tree software in Jalview [39] to evaluate the mutability of this sequence within clinical isolates.

\section{Results and Discussion}

The NRRE-1-DE comprises two half-sites of seven nucleotides, separated by a thymidine nucleotide [5]. Several datasets of HIV-1 LTR sequences were analysed for the presence and conservation of this sequence. The $5^{\prime}$-LTRs analysed are not all from complete genome sequences, and thus the numbering indicated is from the $5^{\prime}$ end of the sequence provided, rather than relative to the TAR element (Figure 1(a)). The NRRE-1-DE was identified within the partial isolates from France and was found to be highly conserved among the 18 isolates (Figure 2(a)). The consensus sequence is $5^{\prime}$-TGACCTTTGGATGG-3' (Figure 2(b)). It was identified at nucleotides $48-61$, with the numbering from the $5^{\prime}$-end of the sequence provided in GenBank. The HIV-1 isolates reported in the dataset from USA also showed almost full conservation of the NRRE-1-DE (Figure 3(a)). It was identified at nucleotides 143-156, with the numbering from the $5^{\prime}$-end of the sequence provided in GenBank. The predominant variation is in the nucleotide position 153, where guanine occurs instead of adenosine in five of the 20 isolates (Figure $3(\mathrm{~b})$ ). The consensus sequence is thus $5^{\prime}$-TGACCTTTGGa/gTGG-3' (Figure 3(b)).

The datasets from Tanzania and India were much larger than those from France and USA, increasing the likelihood of variation within the sequences. In the $5^{\prime}$-LTRs from Tanzania, most of the sequences showed conservation in the NRRE-1-DE (Figure 4(a)). However, 21 out of the 65 sequences showed variation particularly in the first five nucleotides of the NRRE-1-DE (Figure 4(a)). Within this subset of the Tanzanian $5^{\prime}$-LTRs, the second nucleotide was consistently mutated to adenosine. This variability is reflected in the consensus sequence, with three positions showing approximately equal likelihood of being one of two nucleotides: $5^{\prime}-\mathrm{Tg} / \mathrm{aAC} / \mathrm{aTTTGGa} / \mathrm{gTGG}-\mathrm{3}^{\prime}$ (Figure 4(b)). In the small subset of sequences from India which contained whole $5^{\prime}$-LTR sequences, the NRRE-1-DE is almost perfectly conserved amongst the isolates (Figure 5(a)), with the consensus being $5^{\prime}$-TGACCTTTGGg/aTGG-3' (Figure 5(b)). As observed in the sequences from USA and Tanzania, the eleventh nucleotide of the NRRE-1-DE is frequently mutated from adenosine to guanine. There is only one exception 


$\begin{array}{llll}\text { XII-3 } & 1 & \text { CCCTGATTGGCAGAACTACACTGCAGGGCCAGGGATAAGGTATCCACTGACCTTTGGATGG } \\ \text { 2N1T } & 1 & \text { CCCTATTGGCAGAACTACACTGCAGGGCCAGGGATCAGATATCCACTGACCTTTGGTGG } \\ \text { 3N1T } & 1 & \text { CCCTGATTGGCAGAACTACACACCAGGGCCAGGGATCGGATATCCACTGACCTTTGGATGG } \\ \text { 2N2T } & 1 & \text { CCCTGATTGGCAGAACTACACACCAGGACCAGGGATCAGATATCCACTGACCTTGGATGG } \\ \text { IX-B5 } & 1 & \text { CCCTGATTGGCAGAACTACACACCAGGACCAAGGATCAGATATCCACTGACCTTTGGATGG } \\ \text { B2 } & 1 & \text { CCCTGATTGGCAGAACTACACACCAGGGCCAGGGATCAGATATCCACTGACCTTTGGATGG } \\ \text { 3N2T } & 1 & \text { CCCTGATTGGCAGAACTACACACCAGGGCCAGGGATCAGATATCCACTGACCTTTGGATGG } \\ \text { VIII-A2 } & 1 & \text { CCCTGATTGGCAGAACTACACACCAGGGCCAGGGATCAGATATCCACTGACCCTTGGATGG } \\ \text { 2N3T } & 1 & \text { CCCTGATTGGCAGAACTACACACCAGGGCCAGGGATCAGATATCCACTGACCCTTGGATGG } \\ \text { I-B4 } & 1 & \text { CCCTGATTGGCAGAACTACACACCAGGGCCAGGGGTCAGATATCCACTGACCTTTGGATGG } \\ \text { VIII-B2 } & 1 & \text { CCCTGATTGGCAGAACTACACACCAGGGCCAGGGATCGGATATCCACTGACCTTTGGATGG } \\ \text { A2 } & 1 & \text { CCCTGATTGGCAGAACTACACACCAGGGCCAGGGATCAGATATCCACTGACCTTTGGATGG } \\ \text { IX-B4 } & 1 & \text { CCCTGATTGGCAGAACTACACACCAGGACCAGGGATCAGATATCCACTGACCTTTGGATGG } \\ \text { X-A2 } & 1 & \text { CCCTGATTGGCAGAACTACACACCAGGACCAGGGATCAGATATCCACTGATCTTTGGATGG } \\ \text { XII-1 } & 1 & \text { CCCTGATTGGCAGAACTACACTGCAGGGCCAGGGATAAGGTATCCACTGACCTTTGATGG } \\ \text { IX-C1 } & 1 & \text { CCCTGATTGGCAGAACTACACACCAGGGCCGGGGATCAGATATCCATTGACCTTTGATGG } \\ \text { I-B2 } & 1 & \text { CCCTGATTGGCAGAACTACACACCAGGGCCAGGGACCAGATATCCACTGACCTTTGGATGG } \\ \text { XIV-1 } & 1 & \text { CCCTGATTGGCAGAACTACACTGCAGGGCCAGGGACCAGGTTTCCACTGACCTATGGGTGG } \\ \text { Consensus } & 1 & \text { CCCTGATTGGCAGAACTACACaCCAGGgCCagGGatCaGaTaTCCACTGACCttTGGaTGG }\end{array}$

(a)

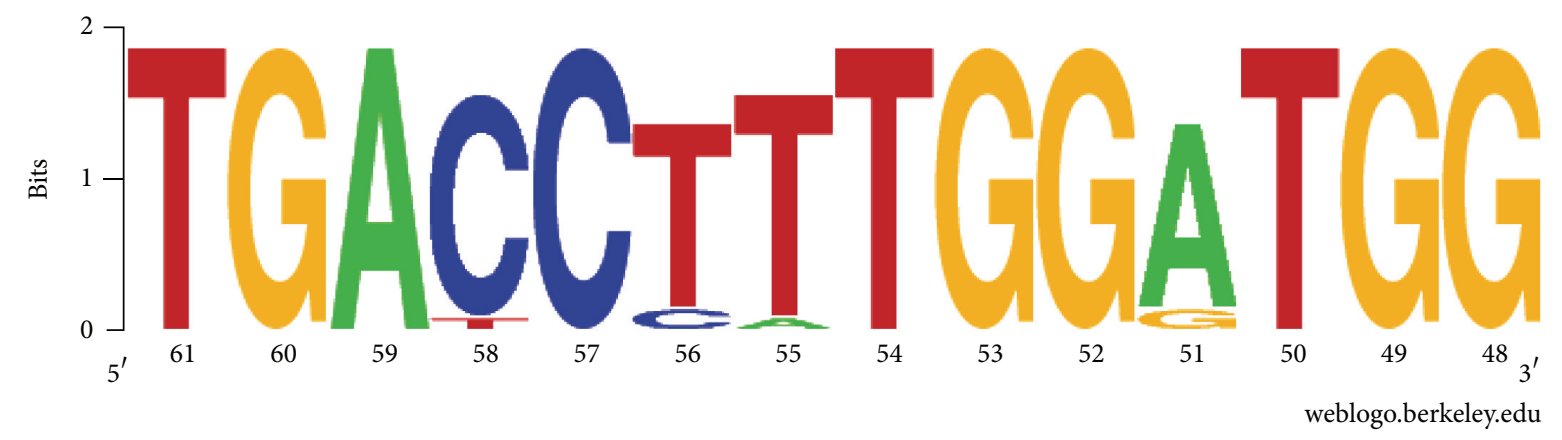

(b)

FIGURE 2: Analysis of the NRRE-1-DE in HIV-1 isolates from France. (a) The HIV-1 5 '-LTR sequences from the isolates were aligned with Clustal W Omega and coloured with Boxshade, with the identical nucleotides shaded black and similar nucleotides coloured grey. The location of the NRRE-1-DE is indicated above the sequence. The consensus sequence is shown below the alignment. (b) Sequence logo of the NRRE1-DE region in the HIV-1 LTRs from viral isolates from France. The individual nucleotides are coloured as follows: thymine, red; guanine, yellow; adenine, green; cytosine, blue. The height of each nucleotide letter indicates its relative frequency at that position within the motif. The presence of more than one nucleotide at a given position indicates the relative occurrence of those nucleotides at that location within the sequence. The GenBank accession numbers for the source sequences are DQ336074.1, DQ336076.1, DQ336081.1-DQ336085.1, DQ336087.1, DQ336089.1, DQ336091.1, and DQ336091.1.

to this (isolate NT6.1, Figure 4(a)), suggesting that the presence of adenosine or guanine at this site is particularly favourable to the virus.

The large dataset from India included multiple clones of several of the isolates. The inclusion of all of these sequences in a single alignment was difficult, not in the least due to variations that could represent viral quasispecies within a single individual. To analyse these sequences, clones of each isolate were grouped and examined for the presence of the NRRE-1-DE, using the consensus sequence from Figure 5(b) for comparison. Those sets of isolates which had two or more clones with the NRRE-1-DE and two without it were aligned and distance trees were calculated (Figure 6). Of the A35/01 and 2/567 isolates, there are three clones that are identical to the consensus sequence and two clones that are very different (Figures 6(a) and 6(c)), showing divergence of the sequences (Figures 6(b) and 6(d)). The KR6 isolate clones all vary from the consensus sequence at the fifth nucleotide, while three of the isolates also vary in the second nucleotide (Figure 6(e)). Thus, the clones from this isolate show little divergence from the consensus sequence or variation from one another (Figure 6(f)). The presence of multiple variants of the NRRE-1-DE in clinical isolates could reflect the emergence of viral quasispecies within a single individual. However, 
the generally high conservation of this sequence over the almost 20 years since Ladias' study and across a wide geographical area suggests that this region confers an advantage to the virus in situ.

The importance of the NRRE-1-DE sequence for regulation of HIV-1 replication in T cells was recognised early in the study of the virus [31]. Interestingly, the authors found that protein binding to the NRRE-1-DE sequence was essential for the inhibition of HIV-1 LTR-mediated transcription [31]. Thus, the mechanism of repression involved direct binding of an NR to the sequence. Based on the early studies on PPRE sequences, it is feasible that the sequence described by Ladias [5] as the NRRE-1-DE is a PPRE. The $5^{\prime}$ half-site is a perfect match for the consensus sequence $5^{\prime}$-TGACCTT$3^{\prime}$ [15]. Indeed, the reported sequences of functional PPREs show variability in this sequence, particularly in the $3^{\prime}$ half-site (Table 1). The NRRE-1-DE sequences in the HIV-1 LTRs described herein are thus similar in sequence to the functional PPREs reported (Table 2), and the high level of conservation of this sequence suggests that it could confer an evolutionary advantage to the virus.

More recently, a study showed that PPAR $\gamma$ binds to the NRRE-1-DE although this binding was not required for the inhibition of HIV-1 transcription by a PPAR $\gamma$ agonist [29]. The entire NRRE-1-DE sequence was used in this study, and thus the particular part of the sequence which forms the PPRE is not described [29]. This study also draws a distinction between PPAR binding to the $5^{\prime}$-LTR and functional effects of PPAR agonists. This is an important distinction since treatment of the cells with a prostaglandin resulted in effects on NF- $\kappa \mathrm{B}$ activation and nuclear translocation that were independent of PPAR activation, yet PPARs were clearly able to bind to the NRRE-1-DE sequence. Thus, it is possible that multiple mechanisms of action of PPAR agonists on HIV1 replication exist, not all of which are mediated via PPAR binding to the PPRE.

Importantly, treatment of monocytes and macrophages with NR ligands has been found to block HIV-1 replication in these cells [40]. The authors show that the mechanism of repression by the activated NRs involves the trans-repression of other transcription factors that bind to the $5^{\prime}$-LTR, notably NF- $\kappa \mathrm{B}$ [40]. The mechanism is receptor dependent, unlike another study in which a PPAR $\gamma$ agonist inhibited NF- $\kappa$ B nuclear translocation in a receptor-independent manner [29]. Elsewhere, the trans-repression of NF- $\kappa$ B by PPAR $\alpha$ involved the binding of the interaction of the receptor with the p65 subunit [41]. In this study, the use of a PPAR $\gamma$ agonist shows that this isoform can also inhibit recruitment of the p65 subunit of NF- $\kappa \mathrm{B}$ [40]. Importantly, PPAR $\gamma$ could be more physiologically relevant than PPAR $\alpha$ in the macrophages used in the study, given the presence of macrophage-specific PPAR $\gamma$ isoforms 4 and 5 [7]. Indeed, the anti-inflammatory action of PPARs generally is thought to occur via a ligand-dependent trans-repression of transcription factor activation $[9,29]$.

The trans-repression of NF- $\kappa \mathrm{B}$ could be critical for the inhibition of HIV-1 replication observed with PPAR ligands, although this does not require PPAR binding to the proviral DNA. It has previously been found that the presence and activation of NF- $\kappa \mathrm{B}$ in T cells is required for HIV-1 integration
TABLE 2: The consensus sequences of the NRRE-1-DE found in the 5 -LTRs of the HIV-1 isolates, compared to the published sequence [5] and the consensus from the cellular metabolism genes [15]. The spacer nucleotide between the half-sites is shown in boldface text.

\begin{tabular}{lc}
\hline HIV-1 $5^{\prime}$ LTRs & NRRE-1-DE sequences $\left(5^{\prime}-3^{\prime}\right)$ \\
\hline France & TGACCT $T$ TGGATGG \\
USA & TGACCT TTGGa/gTGG \\
Tanzania & Tg/aACc/aTTTGGa/gTGG \\
India & TGACCT TTGGg/aTGG \\
Consensus & TGACCTTTGGa/gTGG \\
Published sequence & TGACCT TTGGATGG \\
Cellular consensus & TGACCTt/aTGACCT \\
\hline
\end{tabular}

[42]. Further, the binding of NF- $\kappa$ B to the $5^{\prime}$-LTR is critical in the reactivation of HIV-1 from latency [43], and the induction of NF- $\kappa$ B activity in HIV-1-infected cells leads to increased transcription of the viral RNA [29]. An early study found that an unidentified nuclear matrix protein (NMP) was able to negatively regulate the binding of NF- $\kappa$ B to the $5^{\prime}$-LTR [44]. The NMP was found to bind to the NRE in the $5^{\prime}$-LTR and to be a trans-acting inhibitor of the binding of NF- $\kappa$ B to the LTR [44]. The NMP was not identified but the size $(55-57 \mathrm{kDa})$ is consistent with it being a PPAR isoform. However, the NMP also binds to the DNA of the NRE in a sequence-specific manner to a matrix attachment region that is upstream $(-290$ to -43$)$ of the NRRE-1-DE $(-358$ to -320$)$ [44]. Thus, if it is a PPAR isoform, this upstream region could also contain a PPRE although no such sequence was identified at that site.

In addition to the trans-repression mechanism described above, it is also feasible that the direct binding of PPARs or other NRs to the NRRE-1-DE could lead to a downregulation of viral transcription. The ability of PPARs to repress transcription by directly binding to the PPRE has been demonstrated for cellular genes. The treatment of cells with the PPAR $\gamma$ agonist, rosiglitazone, or overexpression of PPAR $\gamma$ resulted in the downregulation of the endoplasmic reticulum chaperone protein ERp44 [45]. Further, mutation or deletion of the putative PPRE in ERp44 resulted in the loss of this PPAR $\gamma$-mediated repression [45]. Similarly, promoter activity of Wilms' tumour suppressor 1 (WT1) is directly repressed by PPAR $\beta$ in a PPRE-dependent manner [28]. Recently, a computational method has been reported which analysed PPRE sequences from the human genome [25]. Using the computation method to identify PPREs found that downregulated genes were not selected, indicating that the method by which PPARs suppress gene expression is not via binding to PPREs [25]. Indeed, PPRE-dependent transcriptional repression has been demonstrated for cellular genes and the underrepresentation of PPREs from such genes in the computational method does not necessarily rule out this mode of transcriptional repression. Thus, it is possible that PPAR binding to a PPRE in the $5^{\prime}$-LTR could result in transcriptional repression. This mechanism could be in addition to or an alternative to trans-repression; the mechanism used could depend upon the cell type and PPAR isoform activated. 


$\begin{array}{llll}\text { P18-86 } & 121 & \text { GGGCCAGGGATCAGATTTCACTGACCTTCGGATGGTGCTTCAAGCTAGTACCAGTTGAG } \\ \text { P15-90 } & 121 & \text { GGGCCAGGGGTCAGACATCCACTGACCTTTGGATGGTGCTTCAAGCTAGTACCAGTGGAG } \\ \text { P15-84B } & 121 & \text { GGGCCGGGGGTCAGATGGCCACTGACCTTGGGATGGTGCTTCAAGCTAGTACCAGTTGAG } \\ \text { P13-95 } & 121 & \text { GGGCCAGGGGTCAGATATCCACTGACCTTTGGATGGTGCTTCAAGCTAGTACCAGTCGAC } \\ \text { P13-85 } & 121 & \text { GGGCCAGGGATCAGATATCCACTGACCTTTGGATGGTGCTTCAAGCTAGTACCAGTTGAG } \\ \text { P10-86 } & 121 & \text { GGGCCAGGGGTCAGATATCCACTGACCTTTGGATGGTGCTTCAAGCTAGTACCAGTTGAG } \\ \text { P7-93 } & 121 & \text { GGGCCAGGGATCAGATATCCACTGACCTTTGGGTGGTGCTTCAAGTTAGTACCAGTTGAG } \\ \text { P7-82B } & 121 & \text { GGGCCAGGGATCAGATATCCACTGACCTTTGGGTGGTGCTTCAAGTTAGTACCAGTTGAG } \\ \text { SP13-90 } & 121 & \text { GGGCCAGGGACCAGATTCCCACTGACCTTTGGATGGTGCTTCAAGCTAGTACCAGTTGAG } \\ \text { SP13-84 } & 120 & \text { GGGCCGGGGATCAGATACCCACTGTGTTTTGGATGGTGCTTCAAGCTAGTACCAGTTGAG } \\ \text { P18-88 } & 121 & \text { GGGCCAGGGGTCAGATTTCCACTGACCTTTGGATGGTGCTTCAAGCTAGTACCAGTTGAG } \\ \text { P18-84 } & 121 & \text { GGGCCAGGGGTCAGATTTCCACTGACCTTTGGATGGTGCTTCAAGCTAGTACCAGTTGAG } \\ \text { P15-86 } & 121 & \text { GGGCCAGGGGTCAGACATCCACTGACCTTTGGATGGTGCTTCAAGTTAGTACCAGTGGAG } \\ \text { P15-84A } & 121 & \text { GGGCCGGGGGTCAGATGGCCACTGACCTTGGGATGGTGCTTCAAGCTAGTACCAGTTGAG } \\ \text { P13-91 } & 121 & \text { GGGCCAGGGGTCAGATATCCACTGACCTTTGGATGGTGCTTCAAGCTAGTACCAGTTGAC } \\ \text { P10-96 } & 121 & \text { GGGCCAGGGGTCAGATATCCACTGACCTTTGGGTGGTCTTCAAGCTAGTACCAGTTGAT } \\ \text { P10-84 } & 121 & \text { GGGCCAGGGGTCAGATATCCACTGACCTTTGGATGGTGCTTCAAGCTAGTACCAGTTGAG } \\ \text { P7-85 } & 121 & \text { GGGCCAGGGATCAGATATCCACTGACCTTTGGGTGGTGCTTCAAGTTAGTACCAGTTGAG } \\ \text { P7-82A } & 121 & \text { GGGCCAGGGATCAGATATCCACTGACCTTTGGGTGGTGCTTCAAGTTAGTACCAGTTGAG } \\ \text { SP13-93 } & 121 & \text { GGGCCAGGGACCAGATTTCCCCTGACCTTTGGATGGTGCTTCAAGCTAGTACCAGTTGAG } \\ \text { Consensus } & 121 & \text { GGGCCaGGGgtCAGAtatCCaCTGaCCTTtGGaTGGTGCTTCAAGCTAGTACCAGTtGAg }\end{array}$

(a)

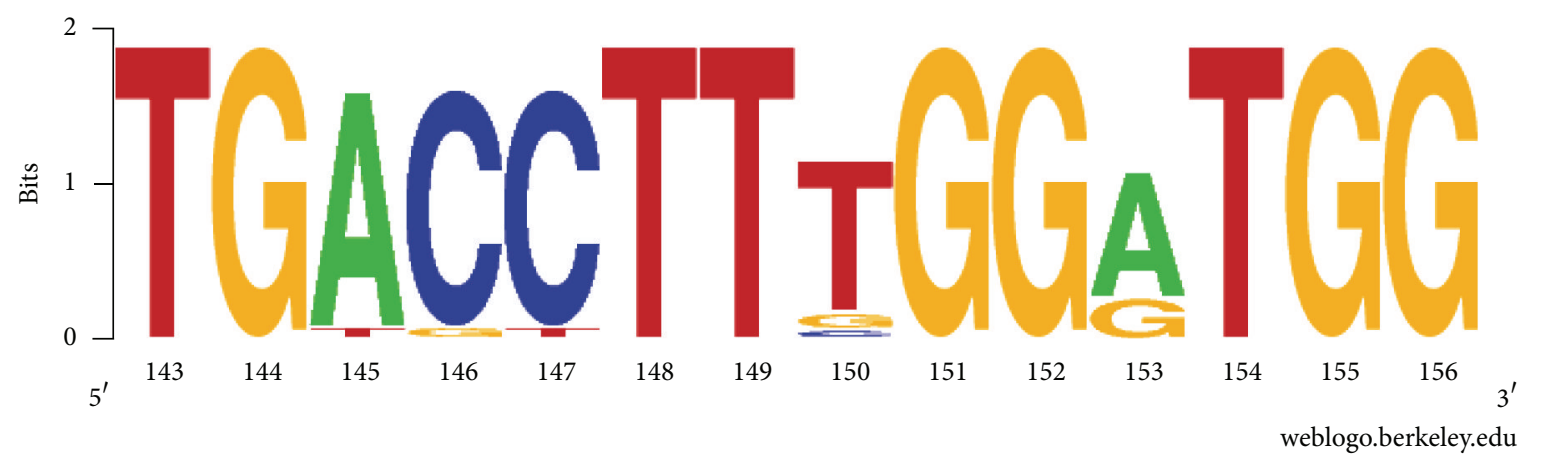

(b)

FIGURE 3: The NRRE-1-DE sequence is highly conserved in HIV-1 isolates from USA. (a) The alignment of the $5^{\prime}$-LTR sequences from the beginning of the sequence provided, with identical nucleotides in black and similar nucleotides in grey. The position of the NRRE-1-DE is indicated above the sequences. (b) Sequence logo of the NRRE-1-DE in the 5 '-LTRs of HIV-1 from USA isolates, showing conservation of nucleotides throughout the motif with degeneracy at positions 150 and 153 . The colour scheme is as indicated in the legend for Figure 2. The GenBank accession numbers for the source sequences are AY376247.1-AY376266.1.

There is evidence from the earliest paper on NRs and the HIV-1 $5^{\prime}$-LTR that an alternative mechanism of repression is possible. In a reporter gene assay, the PPAR/RXR heterodimer did not activate HIV-1 transcription relative to control in the absence of ligands [5]. The addition of ligands for both receptors resulted in a $100 \%$ increase in reporter gene activity [5]. Interestingly, the PPAR/RXR heterodimer could bind to the NRRE-1-DE in the absence of ligand even though it was unable to activate reporter gene expression. In light of other studies showing an inhibitory effect of nonligand-bound PPAR/RXR binding to the PPRE, it is feasible that the lack of activation observed in this assay in fact represents a suppression of transcription. Given the parameters of the experiment, it is impossible to do more than hypothesising about this mechanism but it warrants further investigation.

Importantly, ligand activation RXR, the binding partner of PPAR, could be more critical for regulating HIV1 transcription. In the presence of ligand, both the $\mathrm{RXR} \alpha$ homodimer and the $\operatorname{RXR} \alpha / \operatorname{RAR} \alpha$ heterodimer resulted in greater activation of the reporter gene than that observed with PPAR/RXR $\alpha$ [5]. The effect of retinoids on HIV-1 transcription has been found to be stimulatory and inhibitory, depending upon the cell type. In oligodendroglioma cells, $\operatorname{RXR} \alpha$ and RAR $\alpha$ activated LTR-mediated transcription in the absence of ligand, and this effect was reversed by the addition of ligands [46]. Further, the retinoid receptors were able to antagonise transcription factors (c-Jun, COUP-TF, AP-1) 


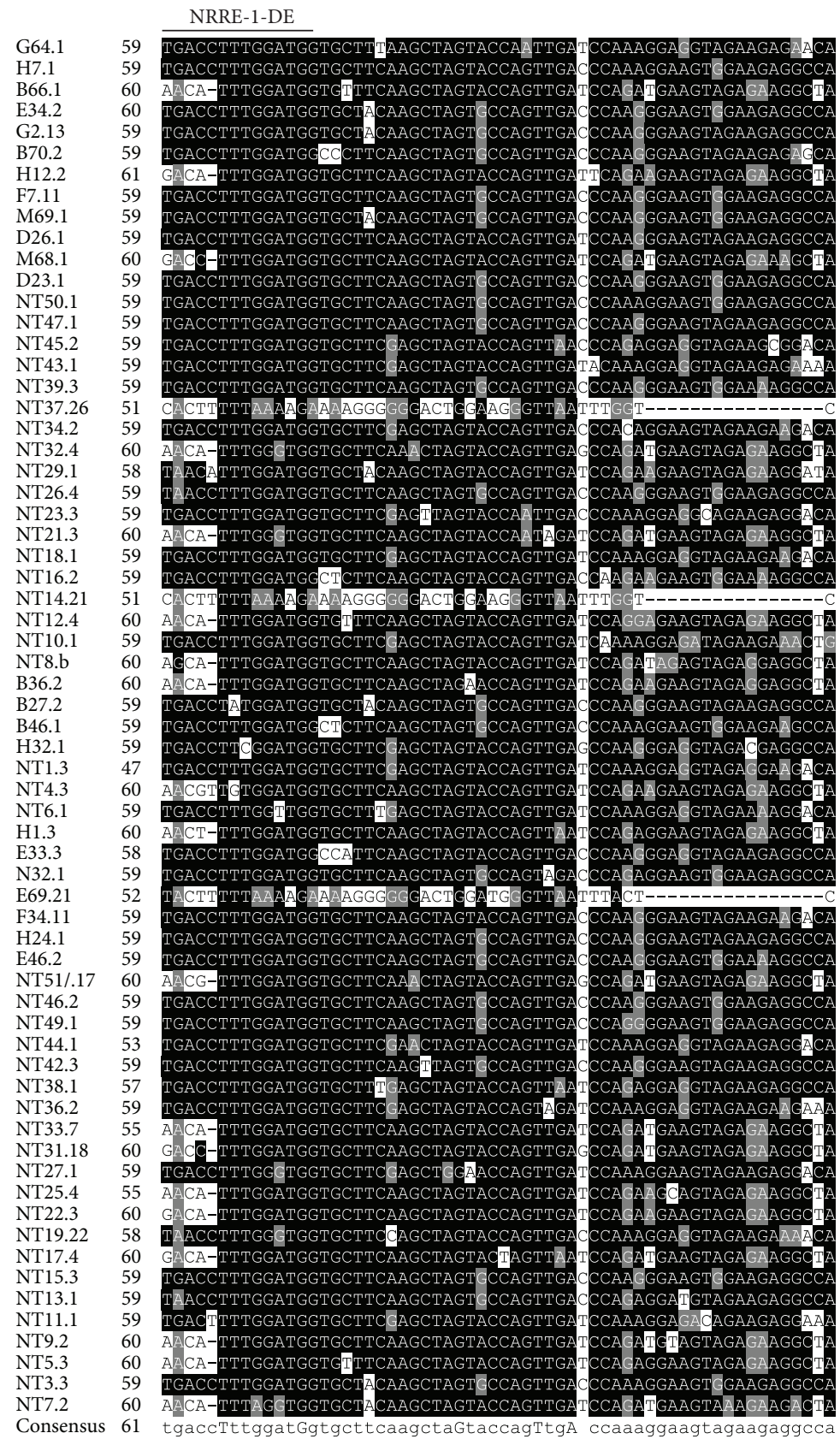

(a)

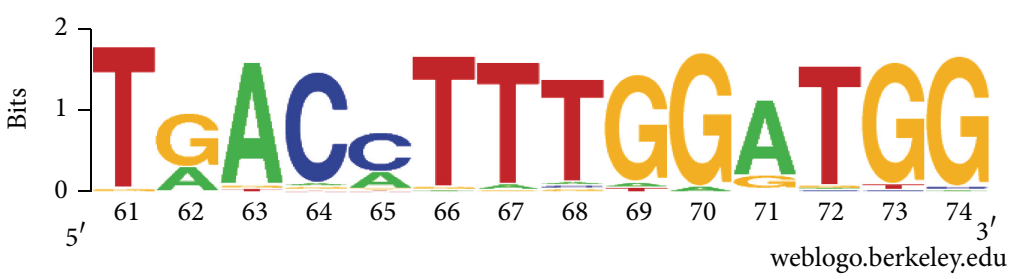

(b)

FIgURE 4: The NRRE-1-DE in the $5^{\prime}$-LTR of HIV-1 isolates from Tanzania. (a) The alignment of the $5^{\prime}$-LTR sequences from the beginning of the sequence provided, with the location of the NRRE-1-DE indicated above the sequences. The alignment was coloured with Boxshade, with identical nucleotides shown in black and similar nucleotides shown in grey. (b) Sequence logo of the NRRE-1-DE in the HIV-15'-LTR isolates from Tanzania, showing conservation of the nucleotide sequence in most positions but with degeneracy in nucleotide positions 62 and 65 . The colour scheme is as indicated above for Figure 2. The GenBank accession numbers for the source sequences are AF254673.1-AF254736.1. 


\begin{tabular}{|c|c|c|}
\hline S375 & 121 & GT \\
\hline S131 & 121 & \\
\hline-529 & 121 & \\
\hline $2-570$ & 121 & CCCAAGGGAAG \\
\hline HY49 & 121 & CCAGTTC \\
\hline Seva & 121 & CTTTGGGTGGCTCTTC \\
\hline $02-7$ & 121 & СTTTGGGTGGTGCTTC \\
\hline S179 & 121 & GTGCTT \\
\hline S398 & 121 & AGTTG \\
\hline Hy6 & 121 & AAGCTAGTACCAGTGGZ \\
\hline 3-BL61 & 121 & AGCTAGTACCAGTTGAC \\
\hline BL42 & 121 & AAGCTAGTACCAGTTAAC \\
\hline S237 & 121 & AGCTAGTAC \\
\hline S080 & 121 & AAGCTA \\
\hline $02-9$ & 121 & AGCTAGTACCAGTT \\
\hline KR22 & 121 & TGCTACAAGCTAGTACCAGTTGACC \\
\hline KR6 & 121 & STGCTTCAAGCTGGTACCAGTTGAACCAGGG \\
\hline $02-538$ & 121 & GTGCTTCAAGCTAGTACCAGTTGACCCAAAG \\
\hline $02-6$ & 121 & TGCTTCAAGCTAGTGCCAGTT \\
\hline S189 & 121 & GTGCTTCAAGCTAGTACCAGTTGAC \\
\hline Consensus & & \\
\hline
\end{tabular}

(a)

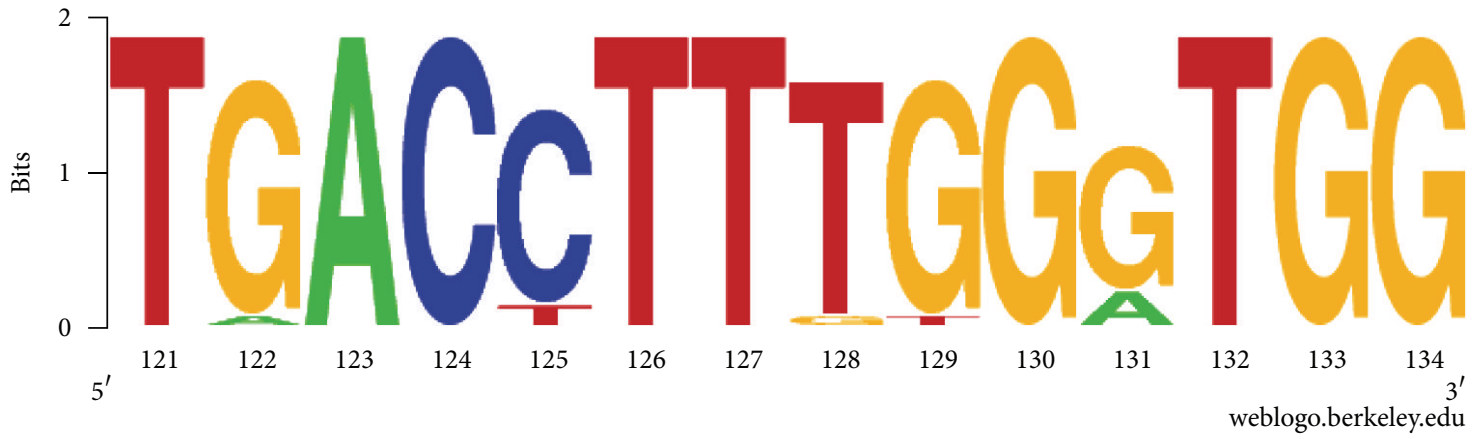

(b)

FIGURE 5: The NRRE-1-DE sequence in the $5^{\prime}$-LTR sequences of HIV-1 isolates from India. (a) The $5^{\prime}$-LTRs of the HIV-1 isolates for which the whole sequence was available were aligned with Clustal W Omega and then coloured with Boxshade, with identical nucleotides shown in black and similar nucleotides in grey. The NRRE-1-DE sequence is indicated above the alignment. (b) The consensus sequence of the NRRE1-DE represented using Weblogo, showing conservation of the nucleotides at most positions but with evidence of degeneracy at position 131. The colour scheme is as indicated for Figure 2. The GenBank accession numbers for the source sequences are HQ202921.1-HQ202943.1.

in an NRRE-1-dependent manner [46]. Although these effects were specific to one cell type within the brain, there are other reports of the repressive effects of retinoids on HIV1 transcription. This includes the more recent finding that the treatment of HIV-1-infected monocytes and macrophages with retinoids inhibited viral replication [47]. Thus, the role of retinoids and RXR activation should not be overlooked in analysing PPAR binding to and activation or repression of the $5^{\prime}$-LTR.

\section{Conclusion}

The present study has shown that the NRRE-1-DE sequence is conserved among HIV-1 isolates from geographically distinct regions and over an extended period of time. The NRRE1-DE as a whole has been shown to be a binding site for multiple NRs, including PPAR, and this binding has resulted in reporter gene activation in the presence of ligand. Importantly, the treatment of cells with PPAR $\gamma$ agonists resulted in the inhibition of HIV-1 replication in macrophages and monocytes by a receptor-dependent trans-repression mechanism [40], whether a PPRE-dependent repression of HIV-1 transcription also occurs and whether the NRRE-1-DE is the site of PPAR binding to the $5^{\prime}$-LTR remains to be determined. Further studies such as chromatin immunoprecipitation could be done to analyse binding of PPARs to this region. In addition, functional studies are needed to determine if this sequence is relevant to HIV-1 replication. The first way 


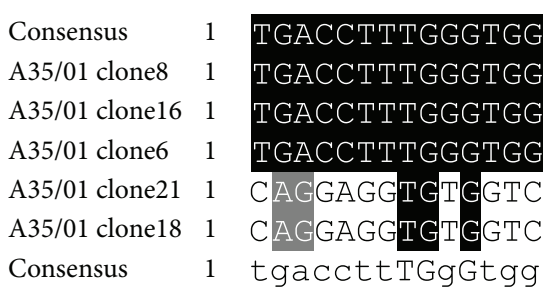

(a)

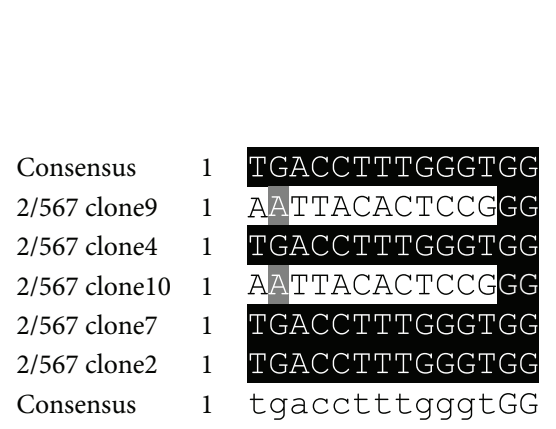

(c)

$\begin{array}{lll}\text { Consensus } & 1 & \text { TAACCTTTGGGTGG } \\ \text { KR6 clone5 } & 1 & \text { TAACTTTTGGGTGG } \\ \text { KR6 clone8 } & 1 & \text { TAACTTTTGGGTGG } \\ \text { KR6 clone10 } & 1 & \text { TAACTTTTGGGTGG } \\ \text { KR6 clone6 } & 1 & \text { TAACTTTTGGGTGG } \\ \text { KR6 clone4 } & 1 & \text { TAACTTTTGGGTGG } \\ \text { Consensus } & 1 & \text { TgAC TTTGGGTGG }\end{array}$

(e)

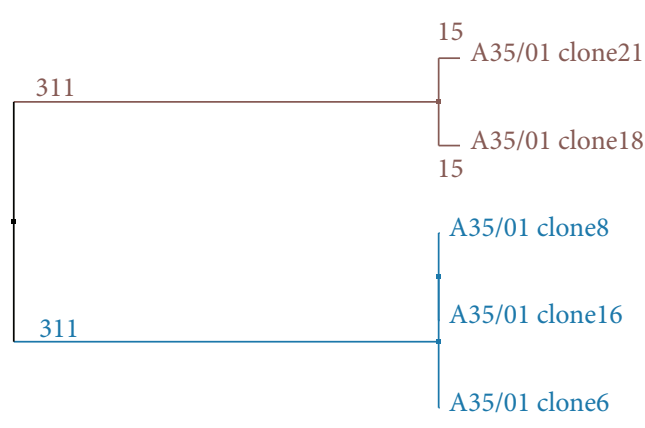

(b)

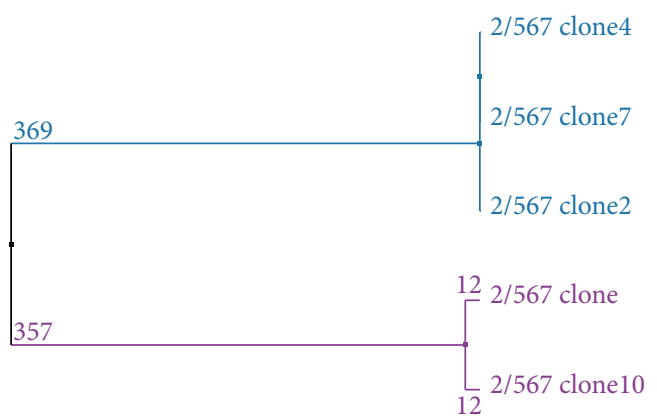

(d)

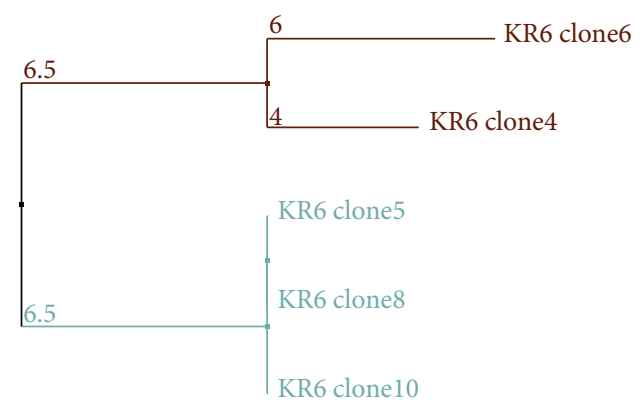

(f)

FIGURE 6: Analysis of variation in the NRRE-1-DE among clones of isolates in the partial sequences from India. The NRRE-1-DE consensus sequence from Figure 5 is used as for comparison to the clones of the isolates by sequence alignment (a, c, and e) and distance-based clustering using Blosum62 (b, d, and e). The isolates examined were A35/01 ( $\mathrm{a}$ and b), 2/567 ( $\mathrm{c}$ and d), and KR6 (e and f). The GenBank accession numbers for the source sequences are JQ268631.1-JQ268635.1 (A35/01); JQ268643.1-JQ268647.1 (2/567); and JQ268707.1-JQ268711.1 (KR6).

to analyse the function of this motif would be to do reporter gene assays using HIV-1 LTR-luciferase constructs and generating point mutations or deletions. The responsiveness to PPAR ligands or to the overexpressed PPARs could then be assessed using luciferase activity as a readout.

The full understanding of how host cell proteins are used by the virus during replication could facilitate the production of novel therapeutics [48]. The studies discussed herein have demonstrated that NR agonists inhibit HIV-1 replication in cells, as well as inhibiting monocyte uptake and $\mathrm{T}$ cell trans-infection [49]. In particular, the inhibition of NF- $\kappa \mathrm{B}$ activation by NR agonists is a mechanism that could be exploited for the development of new drugs. These findings suggest that treatment of HIV-1 infection with NR agonists should be investigated further. In particular, the use of NR agonists as a topical microbicide could limit the early stages in infection, and there are several features of these agonists that make them suitable for such a route of administration [40]. The addition of NR agonists to antiretroviral treatment regimens could be particularly helpful in eliminating latent viral reservoirs including macrophages which are considered to be a key source of latent HIV-1 [40]. Since the intestinal tract can be a critical site of infection, the finding that PPAR agonists inhibited HIV-1 replication in intestinal epithelial cells [29] justifies further studies into the use of these drugs in the fight against HIV-1 infection.

\section{Acknowledgments}

The author would like to thank Dr. Maxwell Treacy for helpful discussions on this work and Mrs. Grace Hurst for reviewing the paper. 


\section{References}

[1] J. A. Esté and T. Cihlar, "Current status and challenges of antiretroviral research and therapy," Antiviral Research, vol. 85, no. 1, pp. 25-33, 2010.

[2] A. Tacheny, S. Michel, M. Dieu, L. Payen, T. Arnould, and P. Renard, "Unbiased proteomic analysis of proteins interacting with the HIV-1 5' LTR sequence: role of the transcription factor Meis," Nucleic Acids Research, vol. 40, article e168, 2012.

[3] L. A. Pereira, K. Bentley, A. Peeters, M. J. Churchill, and N. J. Deacon, "A compilation of cellular transcription factor interactions with the HIV-1 LTR promoter," Nucleic Acids Research, vol. 28, no. 3, pp. 663-668, 2000.

[4] A. Battistini, G. Marsili, M. Sgarbanti, B. Ensoli, and J. Hiscott, "IRF regulation of HIV-1 long terminal repeat activity," Journal of Interferon and Cytokine Research, vol. 22, no. 1, pp. 27-37, 2002.

[5] J. A. A. Ladias, "Convergence of multiple nuclear receptor signaling pathways onto the long terminal repeat of human immunodeficiency virus-1," The Journal of Biological Chemistry, vol. 269, no. 8, pp. 5944-5951, 1994.

[6] A. Montagner, G. Rando, G. Degueurce, N. Leuenberger, L. Michalik, and W. Wahli, "New insights into the role of PPARs," Prostaglandins, Leukotrienes and Essential Fatty Acids, vol. 85, pp. 235-243, 2011.

[7] A. Ciudin, C. Hernandez, and R. Simó, "Update on cardiovascular safety of PPARgamma agonists and relevance to medicinal chemistry and clinical pharmacology," Current Topics in Medicinal Chemistry, vol. 12, pp. 585-604, 2012.

[8] G. S. Harmon, M. T. Lam, and C. K. Glass, "PPARs and lipid ligands in inflammation and metabolism," Chemical Reviews, vol. 111, pp. 6321-6340, 2011.

[9] A. Yessoufou and W. Wahli, "Multifaceted roles of peroxisome proliferator-activated receptors (PPARs) at the cellular and whole organism levels," Swiss Medical Weekly, vol. 140, article w13071, 2010.

[10] K. L. Gearing, M. Gottlicher, M. Teboul, E. Widmark, and J. A. Gustafsson, "Interaction of the peroxisome-proliferatoractivated receptor and retinoid X receptor," Proceedings of the National Academy of Sciences of the United States of America, vol. 90, no. 4, pp. 1440-1444, 1993.

[11] I. Issemann, R. A. Prince, J. D. Tugwood, and S. Green, "The retinoid $\mathrm{X}$ receptor enhances the function of the peroxisome proliferator activated receptor," Biochimie, vol. 75, no. 3-4, pp. 251-256, 1993.

[12] H. P. Guan, T. Ishizuka, P. C. Chui, M. Lehrke, and M. A. Lazar, "Corepressors selectively control the transcriptional activity of PPAR $\gamma$ in adipocytes," Genes \& Development, vol. 19, no. 4, pp. 453-461, 2005.

[13] N. Viswakarma, Y. Jia, L. Bai et al., "Coactivators in PPARregulated gene expression," PPAR Research, vol. 2010, Article ID 250126, 21 pages, 2010.

[14] V. Perissi and M. G. Rosenfeld, "Controlling nuclear receptors: the circular logic of cofactor cycles," Nature Reviews Molecular Cell Biology, vol. 6, no. 7, pp. 542-554, 2005.

[15] K. Schoonjans, B. Staels, and J. Auwerx, "Role of the peroxisome proliferator-activated receptor (PPAR) in mediating the effects of fibrates and fatty acids on gene expression," Journal of Lipid Research, vol. 37, no. 5, pp. 907-925, 1996.

[16] J. D. Tugwood, I. Issemann, R. G. Anderson, K. R. Bundell, W. L. McPheat, and S. Green, "The mouse peroxisome proliferator activated receptor recognizes a response element in the 5 flanking sequence of the rat acyl CoA oxidase gene," The EMBO Journal, vol. 11, no. 2, pp. 433-439, 1992.

[17] N. J. Woodyatt, K. G. Lambe, K. A. Myers, J. D. Tugwood, and R. A. Roberts, "The peroxisome proliferator (PP) response element upstream of the human acyl CoA oxidase gene is inactive among a sample human population: significance for species differences in response to PPs," Carcinogenesis, vol. 20, no. 3, pp. 369-372, 1999.

[18] O. Bardot, M. C. Clemencet, P. Passilly, and N. Latruffe, "The analysis or modified peroxisome proliferator responsive elements of the peroxisomal bifunctional enzyme in transfected HepG2 cells reveals two regulatory motifs," FEBS Letters, vol. 360, no. 2, pp. 183-186, 1995.

[19] A. IJpenberg, E. Jeannin, W. Wahli, and B. Desvergne, "Polarity and specific sequence requirements of peroxisome proliferatoractivated receptor (PPAR)/retinoid X receptor heterodimer binding to DNA. A functional analysis of the malic enzyme gene PPAR response element," The Journal of Biological Chemistry, vol. 272, no. 32, pp. 20108-20117, 1997.

[20] P. Targett-Adams, M. J. McElwee, E. Ehrenborg, M. C. Gustafsson, C. N. Palmer, and J. McLauchlan, "A PPAR response element regulates transcription of the gene for human adipose differentiation-related protein," Biochimica et Biophysica Acta, vol. 1728, no. 1-2, pp. 95-104, 2005.

[21] D. Gupta, T. L. Jetton, R. M. Mortensen, S. Z. Duan, M. Peshavaria, and J. L. Leahy, "In vivo and in vitro studies of a functional peroxisome proliferator-activated receptor $\gamma$ response element in the mouse pdx-1 promoter," The Journal of Biological Chemistry, vol. 283, no. 47, pp. 32462-32470, 2008.

[22] L. Michalik, J. Auwerx, J. P. Berger et al., "International union of pharmacology. LXI. Peroxisome proliferator-activated receptors," Pharmacological Reviews, vol. 58, no. 4, pp. 726-741, 2006.

[23] H. Castelein, T. Gulick, P. E. Declercq, G. P. Mannaerts, D. D. Moore, and M. I. Baes, "The peroxisome proliferator activated receptor regulates malic enzyme gene expression," The Journal of Biological Chemistry, vol. 269, no. 43, pp. 26754-26758, 1994.

[24] C. Juge-Aubry, A. Pernin, T. Favez et al., "DNA binding properties of peroxisome proliferator-activated receptor subtypes on various natural peroxisome proliferator response elements: importance of the $5^{\prime}$-flanking region," The Journal of Biological Chemistry, vol. 272, no. 40, pp. 25252-25259, 1997.

[25] D. G. Lemay and D. H. Hwang, "Genome-wide identification of peroxisome proliferator response elements using integrated computational genomics," Journal of Lipid Research, vol. 47, no. 7, pp. 1583-1587, 2006.

[26] Y. Okuno, M. Matsuda, Y. Miyata et al., "Human catalase gene is regulated by peroxisome proliferator activated receptor-gamma through a response element distinct from that of mouse," Endocrine Journal, vol. 57, no. 4, pp. 303-309, 2010.

[27] H. Nakshatri and P. Bhat-Nakshatri, "Multiple parameters determine the specificity of transcriptional response by nuclear receptors HNF-4, ARP-1, PPAR, RAR and RXR through common response elements," Nucleic Acids Research, vol. 26, no. 10, pp. 2491-2499, 1998.

[28] J.-F. Michiels, C. Perrin, N. Leccia, D. Massi, P. Grimaldi, and N. Wagner, "PPAR $\beta$ activation inhibits melanoma cell proliferation involving repression of the Wilms' tumour suppressor WT1," Pflugers Archiv European Journal of Physiology, vol. 459, no. 5, pp. 689-703, 2010. 
[29] M. Boisvert, S. Côté, A. Vargas et al., "PGJ, antagonizes NF$\kappa \mathrm{B}$-induced HIV-1 LTR activation in colonic epithelial cells," Virology, vol. 380, no. 1, pp. 1-11, 2008.

[30] Y. Lu, N. Touzjian, M. Stenzel, T. Dorfman, J. G. Sodroski, and W. A. Haseltine, "Identification of cis-acting repressive sequences within the negative regulatory element of human immunodeficiency virus type 1," Journal of Virology, vol. 64, no. 10, pp. 5226-5229, 1990.

[31] K. Orchard, N. Perkins, C. Chapman et al., "A novel Tcell protein which recognizes a palindromic sequence in the negative regulatory element of the human immunodeficiency virus long terminal repeat," Journal of Virology, vol. 64, no. 7, pp. 3234-3239, 1990

[32] G. Marsili, A. L. Remoli, M. Sgarbanti, E. Perrotti, A. Fragale, and A. Battistini, "HIV-1, interferon and the interferon regulatory factor system: an interplay between induction, antiviral responses and viral evasion," Cytokine \& Growth Factor Reviews, vol. 23, pp. 255-270, 2012.

[33] G. A. Ferraro, J. P. Monteiro-Cunha, F. M. C. Fernandes et al., "Molecular characterization of long terminal repeat sequences from Brazilian human immunodeficicency virus type 1 isolates," AIDS Research and Human Retroviruses, vol. 29, no. 5, pp. 837841, 2013.

[34] M. Vallejos, F. Carvajal, K. Pino et al., "Functional and structural analysis of the internal ribosome entry site present in the mRNA of natural variants of the human immunodeficiency virus type 1," PLoS ONE, vol. 7, no. 4, Article ID e35031, 2012.

[35] J.-C. Lefebvre, D. March, A. Koechlin, J. Lesimple, and S. Thyss, "Naturally occurring insertion of additional NF-kB motifs and TAR stem loops into HIV-1 LTR, viral amplification and loss of entry into latency," submitted to Genbank.

[36] K. Hiebenthal-Millow, T. C. Greenough, D. B. Bretttler et al., "Alterations in HIV-1 LTR promoter activity during AIDS progression," Virology, vol. 317, no. 1, pp. 109-118, 2003.

[37] J. T. Blackard, B. Renjifo, W. Fawzi et al., "Rapid communication: HIV-1 LTR subtype and perinatal transmission," Virology, vol. 287, no. 2, pp. 261-265, 2001.

[38] M. Bachu, A. B. Mukthey, R. V. Murali et al., "Sequence insertions in the HIV type 1 subtype $\mathrm{c}$ viral promoter predominantly generate an additional NF- $\kappa \mathrm{B}$ binding site," AIDS Research Human Retroviruses, vol. 28, pp. 1362-1368, 2012.

[39] A. M. Waterhouse, J. B. Procter, D. M. A. Martin, M. Clamp, and G. J. Barton, "Jalview version 2-a multiple sequence alignment editor and analysis workbench," Bioinformatics, vol. 25, no. 9, pp. 1189-1191, 2009.

[40] T. M. Hanley and G. A. Viglianti, "Nuclear receptor signalling inhibits HIV-1 replication in macrophages through multiple trans-repression mechanisms," Journal of Virology, vol. 85, no. 20, pp. 10834-10850, 2011.

[41] N. S. Tan, L. Michalik, B. Desvergne, and W. Wahli, "Multiple expression control mechanisms of peroxisome proliferatoractivated receptors and their target genes," Journal of Steroid Biochemistry \& Molecular Biology, vol. 93, no. 2-5, pp. 99-105, 2005.

[42] V. A. Evans, G. Khoury, S. Saleh, P. U. Cameron, and S. R. Lewin, "HIV persistence: chemokines and their signalling pathways," Cytokine \& Growth Factor Reviews, vol. 23, pp. 151-157, 2012.

[43] S. Asin, G. D. Bren, E. M. Carmona, N. J. Solan, and C. V. Paya, "Nf- $\kappa$ B cis-acting motifs of the human immunodeficiency virus (HIV) long terminal repeat regulate HIV transcription in human macrophages," Journal of Virology, vol. 75, no. 23, pp. 11408-11416, 2001.
[44] T. Hoover, J. Mikovits, D. Court, Y.-I. Liu, H.-F. Kung, and Raziuddin, "A nuclear matrix-specific factor that binds a specific segment of the negative regulatory element (NRE) of HIV-1 LTR and inhibits NF- $\kappa$ B activity," Nucleic Acids Research, vol. 24, no. 10, pp. 1895-1900, 1996.

[45] Q. Long, T. Lei, B. Feng et al., "Peroxisome proliferator-activated receptor- $\gamma$ increases adiponectin secretion via transcriptional repression of endoplasmic reticulum chaperone protein ERp44," Endocrinology, vol. 151, no. 7, pp. 3195-3203, 2010.

[46] B. E. Sawaya, O. Rohr, D. Aunis, and E. Schaeffer, "Regulation of human immunodeficiency virus type 1 gene transcription by nuclear receptors in human brain cells," The Journal of Biological Chemistry, vol. 271, no. 37, pp. 22895-22900, 1996.

[47] T. M. Hanley, H. L. B. Kiefer, A. C. Schnitzler, J. E. Marcello, and G. A. Viglianti, "Retinoid-dependent restriction of human immunodeficiency virus type 1 replication in monocytes/macrophages," Journal of Virology, vol. 78, no. 6, pp. 28192830, 2004.

[48] N. Arhel and F. Kirchhoff, "Host proteins involved in HIV infection: new therapeutic targets," Biochimica et Biophysica Acta, vol. 1802, no. 3, pp. 313-321, 2010.

[49] T. M. Hanley, W. B. Puryear, S. Gummuluru, and G. A. Viglianti, "PPAR $\gamma$ and LXR signaling inhibit dendritic cell-mediated HIV-1 capture and trans-infection," PLoS Pathogens, vol. 6, no. 7, Article ID e1000981, 2010. 

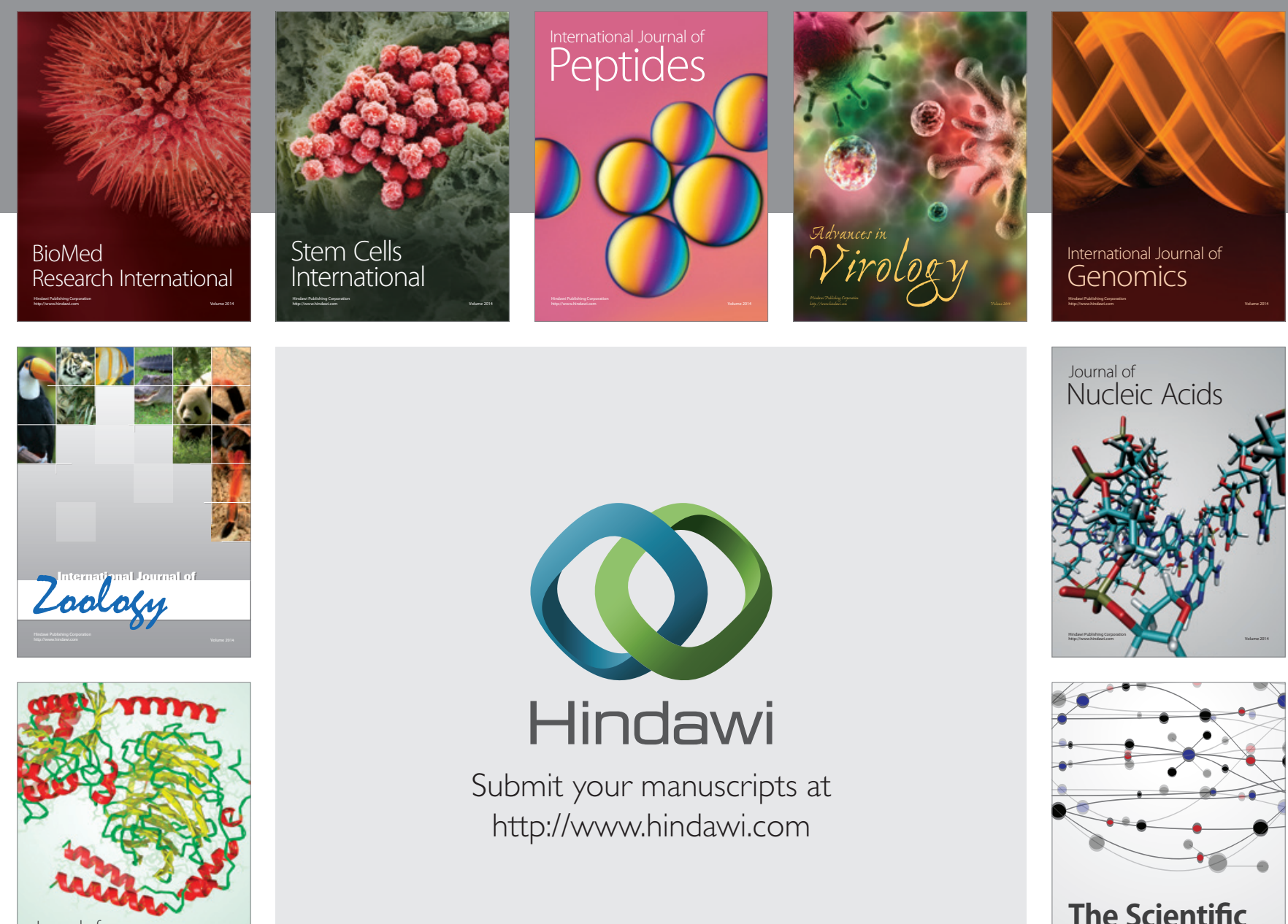

Submit your manuscripts at

http://www.hindawi.com

Journal of
Signal Transduction
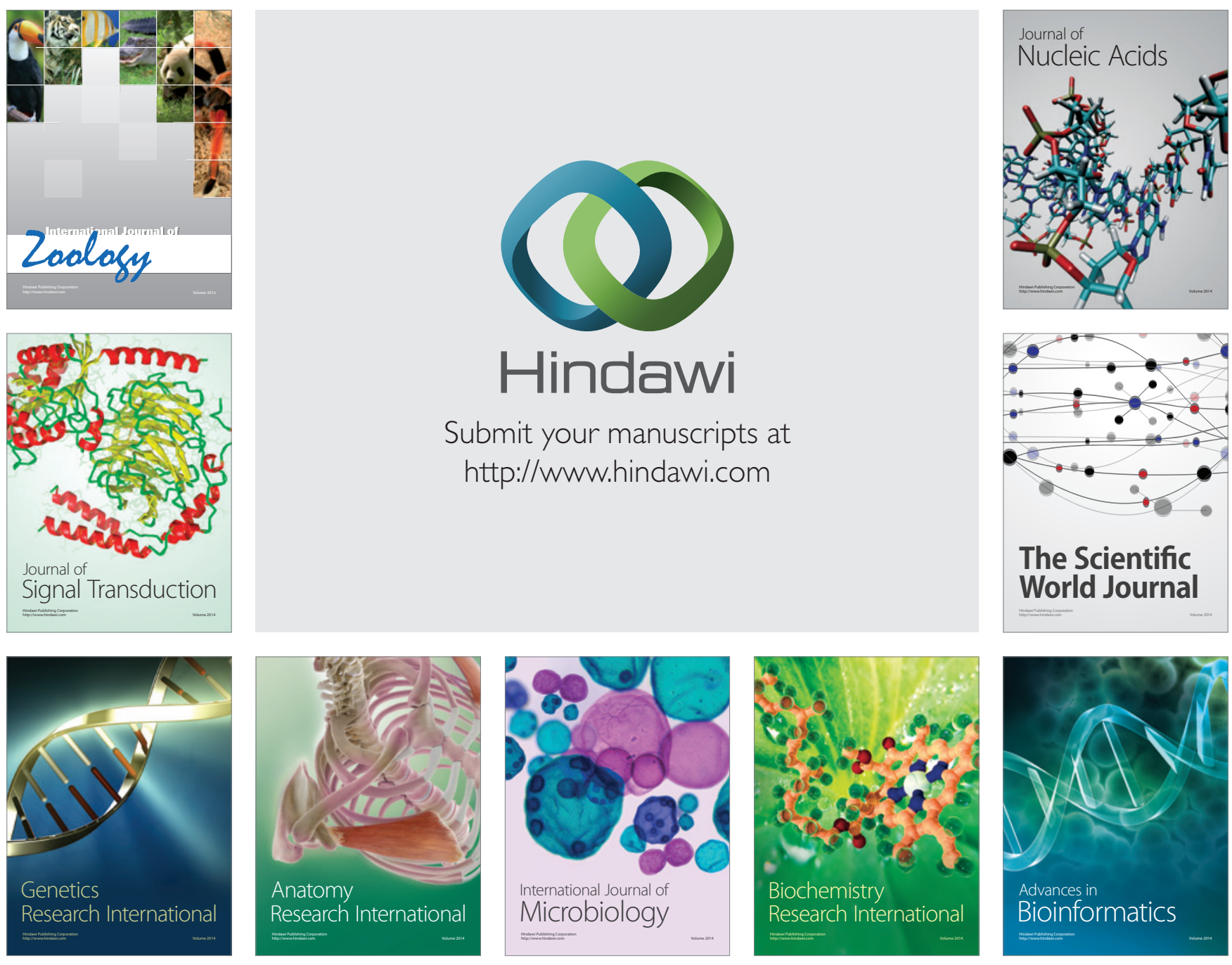

The Scientific World Journal
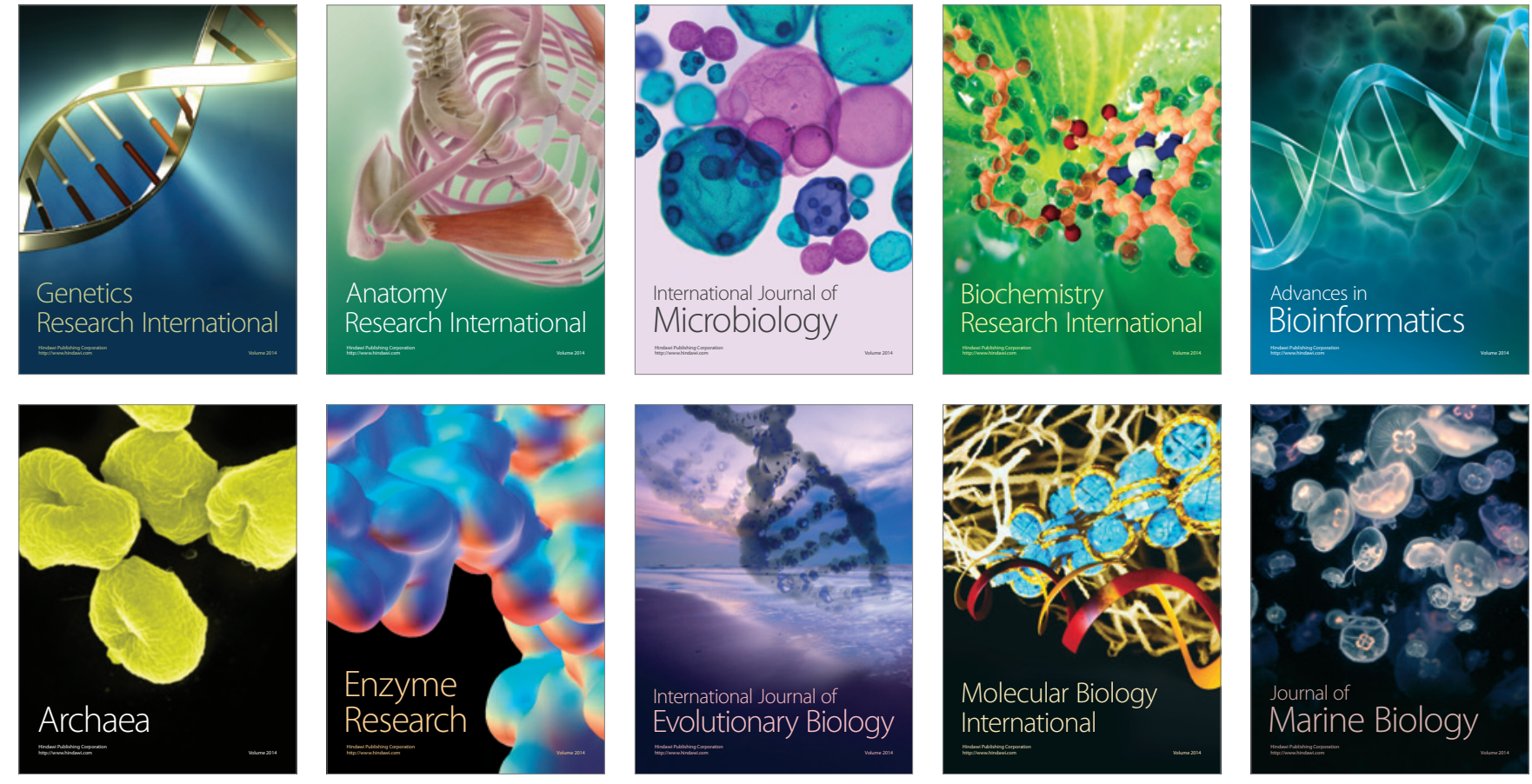